\title{
Analysis of the Variability of Parking Characteristics in A Weekly Distribution in the Conditions of PPZ and DPI Functioning
}

\author{
Agata Kurek $^{1}$, Elżbieta Macioszek ${ }^{1}$ \\ ${ }^{1}$ Silesian University of Technology, Faculty of Transport and Aviation Engineering \\ 40-019 Katowice, Krasińskiego 8 Street, Poland \\ Agata.Kurek@polsl.pl; Elzbieta.Macioszek@polsl.pl
}

\begin{abstract}
Positive changes in the number of cars parked in the city center and a reduction in the average parking time are observed after Paid Parking Zones (PPZ) introduction.. One of the factors influencing the functioning of PPZ is efficient traffic management in the area of PPZ based on reliable traffic measurements and analysis of parking characteristics. The parking characteristics vary with time, i.e. during the day, week, month, and year. The variability of parking characteristics is influenced by many factors, i.a.: the location of parking spaces, the presence of a parking fee and its amount, providing drivers with information about empty parking spaces, etc. The article aimed to analyze the variability of parking characteristics in a weekly schedule under the operating conditions of PPZ and Dynamic Parking Information (DPI). The conducted statistical tests show that the distribution of the value of the use of parking space and the rotation indicator differ between working days and weekend days. In the case of the distribution of the value of the use of parking space between working days, there are no statistical differences, while the distribution of the rotation indicator differs statistically on particular working days. The analysis was performed as a part of research work entitled "Analysis of parking characteristics in the conditions of SPP and DIP functioning in selected areas of GZM cities".
\end{abstract}

Keywords: Paid Parking Zone, Dynamic Parking Information, Friedman test, Wilcoxon test.

\section{Introduction}

Due to the increasing share of individual transport in travel, numerous studies are currently carried out in the field of traffic engineering, which are aimed at finding solutions that can improve road conditions, increase the level of road safety, or reduce the negative impact of transport on the natural environment [1]. These solutions may focus both on the search for new solutions in the field of transport infrastructure, improving the flow of traffic flows in the transport network [2-4] as well as in the field of shaping the appropriate transport policy [5]. The increase in the share of individual transport in travel contributes to significant problems with finding a place to park a vehicle. This is especially noticeable in city centers.

Road traffic has characteristics that change over time. Moreover, these characteristics depend on such features as weather conditions, time of day, day of the week, the presence of non-working days, the period of winter break, summer holidays, etc. [6]. The same factors also affect the variability of the parking characteristics. In addition, the use of parking space may also be influenced by such features as: the location of parking spaces, the presence of a parking fee and its amount, or providing drivers with information about empty parking spaces.

Increasing the availability of parking spaces for more drivers is possible by introducing a Paid Parking Zone (PPZ). The parking fee may contribute to a shorter, necessary parking time. This solution may also discourage drivers from traveling to the city center by car. According to the regulation [7], the fee for parking at PPZ may be collected only on working days in Poland. Another tool that can contribute to increasing the use of parking space is Dynamic Parking Information (DPI). Equipping parking spaces with sensors allows drivers to be informed about the number of free parking spaces, e.g. on variable message tables or via mobile applications or websites.

The article aims to analyze the variability of parking characteristics in a weekly schedule in the conditions of the PPZ and DPI functioning in Gliwice. The city of Gliwice belongs to the Gornoslasko-Zaglebiowska Metropolis (Poland). There is a PPZ in the city center. The fee for parking in PPZ is collected from Monday to Friday from 09:00 to 17:00. There is a DIP on 18 sections of streets (segments) covered by PPZ.

\section{Analysis of the Variability of Parking Characteristics in a Weekly Distribution}

The data was obtained from the Traffic Control Center for the needs of the analysis of the variability of parking characteristics in the weekly distribution in the conditions of PPZ and DIP functioning. The data included the number of 
parking vehicles and the rotation of parking spaces in each segment on each day and hour in 2020. for the analysis was selected the month of February 2020, because from March 2020 road traffic has a different distribution due to the COVID19 pandemic [8-9]. In January 2020, there were non-working days and a winter break period for the Silesian Voivodeship in which the city of Gliwice is located. Figure 1 shows use of the parking space in every hour of the day on particular days of the week, whereas Figure 2 presents the rotation indicator in each hour of the day on particular days of the week. Figure 3 presents use of the parking space in all hours of each day in February, whereas Figure 4 shows the rotation indicator in all hours of each day in February.

The greatest use of parking spaces in the analyzed period occurred on working days, from 07:00 to 15:00 (Fig. 1). The highest rotation in parking spaces in the analyzed period occurred on working days, from 07:00 to 19:00 (fig. 2). The distribution of the use of parking space and the rotation indicator on all working days in the analyzed period is characterized by no significant differentiation.

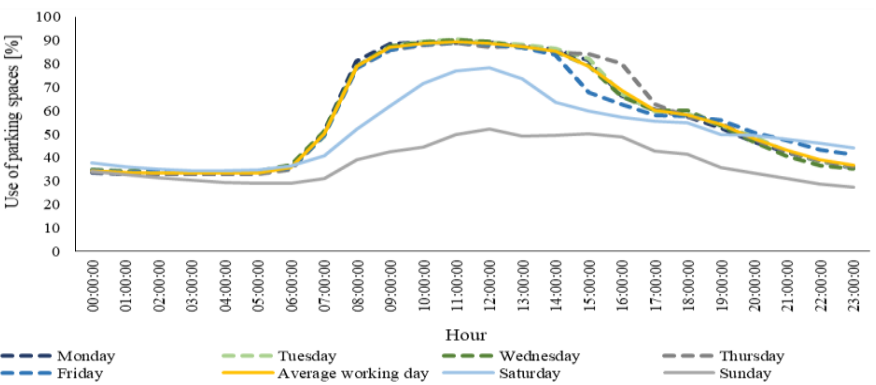

Fig. 1. The average value of the use of parking space in all parking spaces during the day on particular days of the week

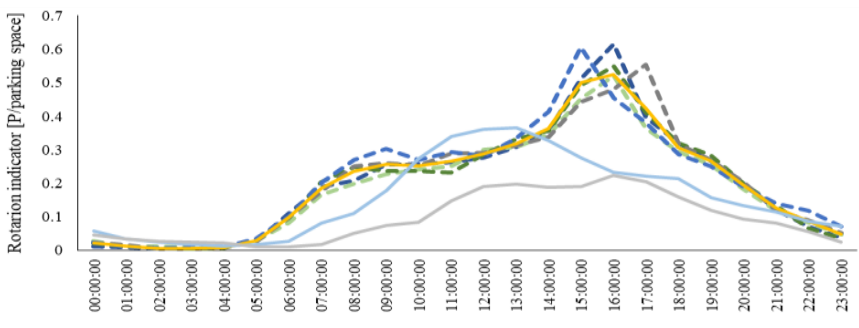

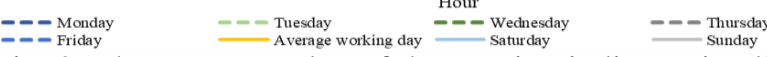

Fig. 2. The average value of the rotation indicator in all parking spaces during the day on particular days of the week

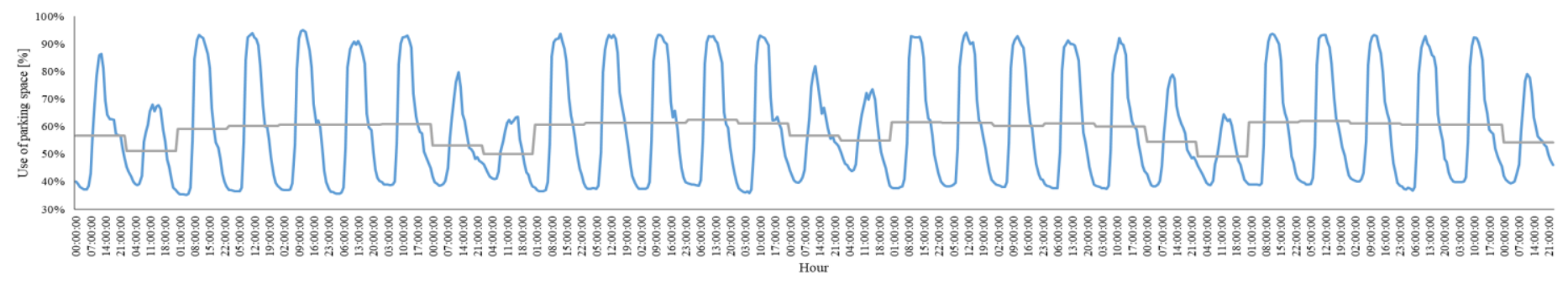

Fig. 3. Average use of parking space in all sections at every hour of the day and on every day in February

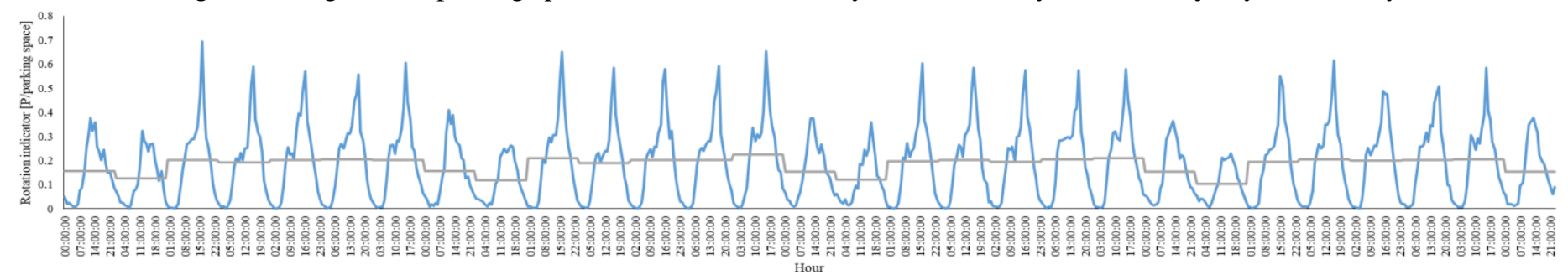

Fig. 4. Average rotation indicator in all sections at every hour of the day and on every day in February

To investigate the variability of parking characteristics in the weekly distribution in the conditions of the SPP and DIP operation, the Friedman test was carried out for the value of the use of parking space and the rotation indicator on all days of the week and working days. Additionally, the Wilcoxon test was performed for the value of the use of parking space and the rotation indicator on all days of the week. Tables 1 and 2 show the results of the Friedman and Wilcoxon test statistics. In turn, Figure 5 shows the box plots for the mean value, standard error, and standard deviation. 
Table 1. Friedman test statistics for use of parking space and rotation indicator in all segments PPZ

\begin{tabular}{|c|c|c|c|c|}
\hline & \multicolumn{2}{|c|}{ Friedman test statistics for all weekdays } & \multicolumn{2}{c|}{ Friedman test statistics for working days } \\
\hline & Use of parking space & Rotation indicator & Use of parking space & Rotation indicator \\
\hline Chi Square & 56.30 & 26.83 & 7.97 & 0.47 \\
\hline p-value & 0 & 0.00016 & 0.93 & 0.014 \\
\hline \multicolumn{7}{|c|}{ The average rank } \\
\hline Monday & 4.08 & 3.97 & 2.58 & 2.65 \\
\hline Tuesday & 5.08 & 3.75 & 3.54 & 2.42 \\
\hline Wednesday & 5.00 & 4.19 & 3.42 & 3.21 \\
\hline Thursday & 4.08 & 4.58 & 2.58 & 3.88 \\
\hline Friday & 4.46 & 5.25 & 2.88 & - \\
\hline Saturday & 4.21 & 4.04 & - & - \\
\hline Sunday & 1.08 & 2.21 & - & \\
\hline
\end{tabular}

Table 2. Wilcoxon test statistics for use of parking space and rotation indicator in all segments PPZ

\begin{tabular}{|c|c|c|}
\hline Days & Use of parking space & Rotation indicator \\
\hline Monday\&Tuesday & $\mathbf{0 . 0 2 5 8 4 3}$ & $\mathbf{0 . 0 3 7 0 0 5}$ \\
\hline Monday\&Wednesday & 0.607053 & 0.855199 \\
\hline Monday\&Thursday & 0.797069 & 0.277606 \\
\hline Monday\&Friday & 0.886403 & $\mathbf{0 . 0 4 5 5 0 1}$ \\
\hline Monday\&Saturday & $\mathbf{0 . 0 4 5 5 0 1}$ & 0.116084 \\
\hline Monday\&Sunday & $\mathbf{0 . 0 0 0 0 2 4}$ & $\mathbf{0 . 0 0 0 4 9 1}$ \\
\hline Tuesday\&Wednesday & 0.558068 & $\mathbf{0 . 0 3 9 6 7 3}$ \\
\hline Tuesday\&Thursday & 0.122866 & 0.063292 \\
\hline Tuesday\&Friday & 0.440454 & $\mathbf{0 . 0 0 8 5 7 5}$ \\
\hline Tuesday\&Saturday & $\mathbf{0 . 0 3 2 1 2 5}$ & 0.161514 \\
\hline Tuesday\&Sunday & $\mathbf{0 . 0 0 0 0 1 8}$ & $\mathbf{0 . 0 0 0 1 4 5}$ \\
\hline Wednesday\&Thursday & 0.607053 & 0.797069 \\
\hline Wednesday\&Friday & 0.188751 & 0.109600 \\
\hline Wednesday\&Saturday & $\mathbf{0 . 0 2 9 9 0 0}$ & 0.122866 \\
\hline Wednesday\&Sunday & $\mathbf{0 . 0 0 0 0 1 8}$ & $\mathbf{0 . 0 0 0 5 4 6}$ \\
\hline Thursday\&Friday & 0.170242 & 0.129954 \\
\hline Thursday\&Saturday & $\mathbf{0 . 0 3 4 4 9 2}$ & 0.091852 \\
\hline Thursday\&Sunday & $\mathbf{0 . 0 0 0 0 2 1}$ & $\mathbf{0 . 0 0 0 1 8 2}$ \\
\hline Friday\&Saturday & $\mathbf{0 . 0 1 5 1 5 9}$ & $\mathbf{0 . 0 2 2 2 7 2}$ \\
\hline Friday\&Sunday & $\mathbf{0 . 0 0 0 0 1 8}$ & $\mathbf{0 . 0 0 0 1 1 5}$ \\
\hline Saturday\&Sunday & $\mathbf{0 . 0 0 0 0 1 8}$ & $\mathbf{0 . 0 0 0 0 8 1}$ \\
\hline
\end{tabular}

where: bold values means $p<0.05$ a).

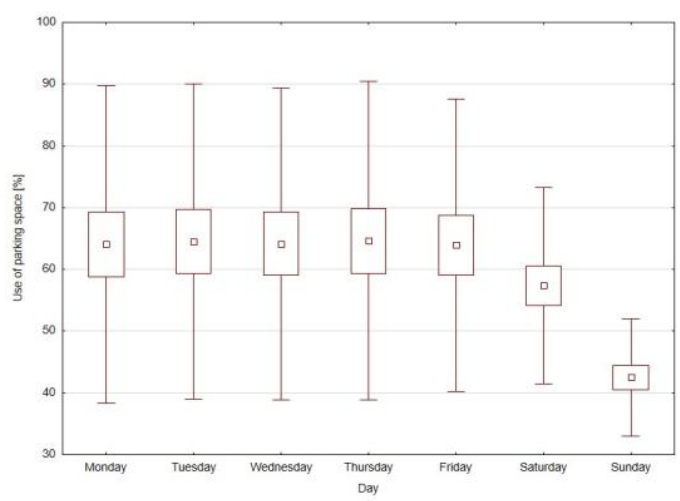

b).

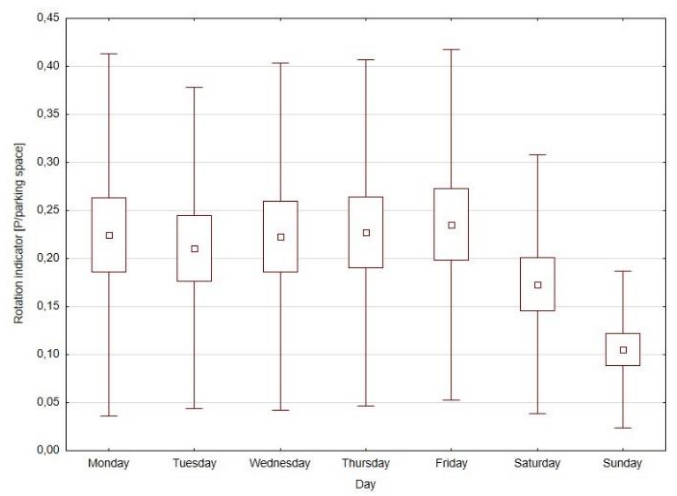

Fig. 5. Box plot for an average weekday in February for: a). use of all parking spaces; b). rotation indicator for all parking spaces

The values in Table 1 indicate that the distribution of the use of parking space and the rotation indicator differs statistically between particular days of the week and that the distribution of the use of parking space does not differ statistically on working days, while the distribution of the rotation indicator differs statistically between particular working days. The values in Table 2 indicate that the use of parking space statistically differs between working days: Monday and Tuesday, between all weekdays and weekend days, and between Saturday and Sunday and on all days of the week the rotation indicator statistically differs between working days: Monday and Tuesday, Monday and Friday, Tuesday and Wednesday, Tuesday and Friday, between weekdays and weekend days: Friday and Saturday, all working days and 
Sunday and between Saturday and Sunday. Figure 4-5 indicate that working days have higher values of error and standard deviation compared to weekend days. Therefore, working days are characterized by greater differentiation in the values of the use of parking space and the rotation indicator during the day compared to weekend days.

\section{Conclusion}

The conducted analyzes for parking spaces in Gliwice allowed for the formulation of the following main conclusions:

- the greatest use of parking spaces in the analyzed period occurred on working days, from 07:00 to 15:00, while the highest rotation in parking spaces in the analyzed period occurred on working days, from 07:00 to 19:00,

- the values of the Friedman test statistics carried out for all days indicate that the distribution of the use of parking space and the rotation indicator differs statistically between particular days of the week. Whereas these conducted for working days indicate that the distribution of the use of parking space does not differ statistically on working days, while the distribution of the rotation indicator differs statistically between particular working days,

- the values of the Wilcoxon test statistics conducted for all days indicate that the use of parking space statistically differs between days: Monday and Tuesday, Saturday and Sunday and between all weekdays and weekend days. The values of the Wilcoxon test statistics performed for all days of the week indicate that the rotation indicator statistically differs between days: Monday and Tuesday, Monday and Friday, Tuesday and Wednesday, Tuesday and Friday, Friday and Saturday, all working days and Sunday and between Saturday and Sunday,

- box plots indicate that working days are characterized by greater differentiation in the values of the use of parking space and the rotation indicator during the day compared to weekend days,

- the results of statistical tests indicate that charging for parking on working days and informing drivers about empty parking spaces may increase the rotation of parking spaces.

\section{Acknowledgments}

The present research has been financed from the "Excellence Initiative - Research University" program implemented at the Silesian University of Technology, 2020-2022 as a part of a grant entitled "Analysis of parking characteristics in the conditions of SPP and DIP functioning in selected areas of GZM cities".

\section{References}

[1] E. Macioszek and A. Kurek, "The Use of a Park and Ride System-A Case Study Based on the City of Cracow (Poland)", Energies, vol. 13, pp. 1-26, 2020.

[2] T. Szczuraszek and E. Macioszek, "Analysis of time intervals distribution between vehicles on roadway arounf central island of small roundabouts." Drogi i Mosty, vol. 9, pp. 87-99, 2010.

[3] E. Macioszek, "The application of HCM 2010 in the determination of capacity of traffic lanes at turbo roundabout entries." Transport Problems, vol. 11, no. 3, pp. 77-89, 2016.

[4] E. Macioszek, "Models of Critical Gaps and Follow-up Headways for turbo Roundabouts." in Macioszek E., Akçelik R., Sierpiński G. (eds) Roundabouts as Safe and Modern Solutions in Transport Networks and Systems. TSTP 2018. Lecture Notes in Networks and Systems. Springer International Publishing Switzerland, 2019, vol. 52, pp. 124-134.

[5] E. Macioszek, P. Świerk and A. Kurek, "The Bike-Sharing System as an Element of Enhancing Sustainable Mobility A Case Study based on a City in Poland", Sustainability, vol. 12, pp. 1-29, 2020.

[6] T. Thomas, W. Weijermars and E. van Berkum, "Variations in urban traffic volumes." European Journal of Transport and Infrastructure Research, vol. 8. no. 3. pp. 251-2632008.

[7] Ministry of infrastructure, Act of March 21, 1985 on public roads, with subsequent changes.

[8] P. Bucsky, "Modal share changes due to COVID-19: The case of Budapest." Transportation Research Interdisciplinary Perspectives, vol. 8, pp. 1-5, 2020.

[9] A. Shamshiripour, E. Rahimi, R. Shabanpour and A. K. Mohammadian, "How is COVID-19 reshaping activity-travel behavior? Evidence from a comprehensive survey in Chicago." Transportation Research Interdisciplinary Perspectives, vol. 7, pp. 1-16, 2020. 